\title{
On Creating and Sustaining Alternatives: The case of Danish Telehealth
}

\author{
Morten Kyng \\ Aarhus University \& The Alexandra Institute \\ Aabogade 34; 8200 Aarhus N; Denmark \\ mkyng@cs.au.dk
}

\begin{abstract}
This paper presents and discusses an initiative aimed at creating direct and long lasting influence on the use and development of telemedicine and telehealth by healthcare professionals, patients and citizens. The initiative draws on ideas, insights, and lessons learned from Participatory Design (PD) as well as from innovation theory and software ecosystems. Last, but not least, the ongoing debate on public finances/economy versus tax evasion by major private companies has been an important element in shaping the vision and creating support for the initiative. This vision is about democratic control, about structures for sustaining such control beyond initial design and implementation and about continued development through Participatory Design projects. We see the "middle element", the structures for sustaining democratic control beyond initial design and implementation as the most important and novel contribution of the paper.
\end{abstract}

\section{Author Keywords}

Contexts for design; sustaining results; control; Participatory Design; software eco-systems; innovation; Open Source; telehealth, telemedicine, healthcare technology.

\section{ACM Classification Keywords}

D.2.10 Design, Methodologies, D.2.m Miscellaneous H.5.m. Information interfaces and presentation (e.g., HCI): Miscellaneous.

\section{INTRODUCTION}

This paper is about how users of technology may achieve direct and long lasting influence on the IT-systems they use. The case presented and discussed is telemedicine and telehealth in Denmark. The main mechanism for achieving this influence is a foundation controlled by healthcare professionals, patients, citizens, public healthcare organizations and researchers. The foundation, called $4 \mathrm{~S}$ [1], controls two sets of open source software: an ITinfrastructure toolbox and a telemedicine/telehealth ${ }^{1}$

Copyright $\subset 2015$ is held by the author(s). Publication rights licensed to Aarhus University and ACM

5th Decennial Aarhus Conference on Critical Alternatives

August 17-21, 2015, Aarhus Denmark

DOI: http://dx.doi.org/10.7146/aahcc.v1i1.21297 platform, called OpenTele. OpenTele is already the most used telehealth platform in Denmark and in January 2015 the five Danish regions, who own the public hospitals, decided to increase its use over the next few years.

$4 \mathrm{~S}$ began as an effort, initiated by researchers, to get the most out of a set of IT infrastructure tools, primarily in terms of benefits for public health service providers and private vendors. $4 \mathrm{~S}$ then developed into what it is today: an organization facilitating direct and long lasting influence by healthcare professionals, patients and citizens.

The key people involved in the development of $4 \mathrm{~S}$ are researchers in Participatory Design (PD), IT managers from the public hospital sector, and - for the last year - doctors and other healthcare personnel working at public hospitals. In recent months people from patients organizations have joined the initiative, and they expect to play a key role in the future. For the PD researchers $4 \mathrm{~S}$ was originally an initiative quite separate from their work in PD. That work was about democracy, mainly in terms of doing design in ways that allowed participating users to contribute in ways that made the outcome more attuned to their interest. $4 \mathrm{~S}$ was about national infrastructure, open source software tools and software ecosystems. However, as it turned out, $4 \mathrm{~S}$ could be developing into a very successful mechanism for sustaining democratic user influence.

One might say that Scandinavian Participatory Design (PD) began as an effort towards extending concerns for workplace democracy to cover IT [2], and gradually, over more than four decades, focused more and more on techniques for $\mathrm{PD}$, see e.g. [3-5]. In contrast, 4S began as an effort to get the most out of a set of IT infrastructure tools, primarily in terms of benefits for private vendors and public health service providers [6]. From there, 4S developed into an organization facilitating and sustaining direct influence on the use and development of telehealth by healthcare professionals, patients and citizens. In doing so $4 \mathrm{~S}$ has added a new type of context for PD in Denmark.

In our view, the case of $4 \mathrm{~S}$, especially how $4 \mathrm{~S}$ changed over time, presents important lessons for those who want to develop and sustain critical, democratic alternatives, and for those who want to contribute to the continued developments of Participatory Design (PD) - especially those who are interested in the relations between PD and its larger setting 
in society. Therefore we describe the development of $4 \mathrm{~S}$ in quite some detail. This description involves quite a few elements: organizations, projects and software. To assist the reader these are listed below:

\section{Regions}

Denmark has five regions whose main task is to administer the public hospitals

\section{Municipalities}

There are 98 municipalities. Their main tasks include administration of prevention, elder care, e.g. nursing homes, and public schools.

\section{OpenTele}

An open source telemedicine/-health platform developed by three of the five Danish regions and used in two large national projects.

\section{Net4Care}

A research project that developed a proposal for a national infrastructure for telehealth.

Net4Care is also the name of an infrastructure toolbox developed by the project.

\section{$4 S$}

A foundation with members from the three regions that developed OpenTele, a municipality, the state level and from OpenTele users and research. The researchers also participated in the Net4Care project.

$4 \mathrm{~S}$ governs two sets of open source software: the Net4Care infrastructure toolbox and the OpenTele telehealth platform

4S has a board, a coordinator, a software group and healthcare forums.

The rest of the paper is organized as follows: First we present 4S: how it began, the steps toward what it is today, and what $4 \mathrm{~S}$ is currently working with. Secondly, we look at why $4 \mathrm{~S}$ might work, i.e. what are the characteristics of telehealth and the societal context that make it possible for an organization like $4 \mathrm{~S}$ to succeed. Then, in the Discussion section, we look at $4 \mathrm{~S}$ in relation to ongoing debates in $\mathrm{PD}$ on democracy and sustaining results - and we briefly reflect on why it took so long to develop the $4 \mathrm{~S}$ initiative. We conclude the paper by a short discussion of what we have learned from $4 \mathrm{~S}$.

\section{THE 4S FOUNDATION - AND HOW IT WAS DEVELOPED}

\section{The First Idea: Shared, Public Infrastructure}

Developing the blueprint for the $4 \mathrm{~S}$ organization began in 2011. The idea was to create an organization to promote and further develop an open source IT-infrastructure toolbox. The toolbox was developed as part of a research project on national infrastructures for telehealth and named Net4Care after the project [6]. The aim of the toolbox was to make it easier for an IT-company to effectively and safely support sharing of health data across health service providers, e.g. hospitals and general practitioners, and across systems from different vendors. And through such sharing make it simpler for the health service providers to create better services. The aim of $4 \mathrm{~S}$ was to support expanding use of the toolbox after the end of the Net4Care project, i.e. to sustain the results of the project. Looking at other similar projects, both research projects and public, open source projects, we believed this to be a major challenge: The results of research projects, like Palcom [7], are not being used nearly as much as intended and thus not developed after the end of the project. Or public open source create animosity due to lack of good documentation, lack of tutorials, and/or a flawed governing structure [6].

\section{The Second Idea: Open Source Telemedicine Platform}

The Net4Care infrastructure toolbox, and the architecture on which it was based, had many merits [6], but it was difficult to create sufficient interest among health service providers and vendors. To them Net4Care was just another research project without backing from strong public or private players. Thus we were heading down the road towards "not being used nearly as much as intended". Two things changed this. First we suggested that $4 \mathrm{~S}$ should also have governance of an open source telehealth platform, called OpenTele. OpenTele was being developed by three of the five Danish regions as part of two large telehealth projects. And the regions saw $4 \mathrm{~S}$ as a way to increase the likelihood of sustaining OpenTele after the end of these two projects. The inclusion of OpenTele, as was our intension, dramatically increased the interest in $4 \mathrm{~S}$ among both these three regions and the healthcare professionals using the OpenTele system. Secondly, the public authority responsible for health IT, The National eHealth Authority, published a so-called reference architecture for telehealth [8]. The Net4Care infrastructure toolbox was fully aligned with this reference architecture. Obviously this dramatically increased the interest in 4S among health IT companies that wanted to understand and use the reference architecture.

Then, in June 2013, the 4S foundation outlined above was formally established, and became copyright holder of the two sets of open source software: the OpenTele platform for telehealth and the Net4Care infrastructure toolbox.

\section{Implementing 4S}

In the following months we focused on four areas: interactions with stakeholders, developing the role of the board, involvement of healthcare professionals and patients, and handling governance of the open source software.

\section{Interactions with main stakeholders:}

\section{Private IT-companies and users of OpenTele}

The first task that $4 \mathrm{~S}$ focused on was creating links with private IT-companies that were potential users of the infrastructure toolbox. To this end we set up an experiment to investigate and illustrate the effectiveness of the toolbox. This resulted in a public demonstration of sharing data across systems of different types, e.g. homecare telehealth 
and electronic patient records, and from different vendors at a conference in 2013 [9]. One of the results was quite strong support from The Confederation of Danish Industry.

Our second task was creating links with the users of OpenTele. This proved to be more difficult than expected, primarily because the two projects using OpenTele were behind schedule, and for that reason were closely followed by their funding agencies. The top-level project managers did not see dialogue with $4 \mathrm{~S}$ as justifiable amidst difficulties in catching up, and thus did not want to facilitate cooperation between project participants and 4S. However, one of the sub-projects, the one on complicated pregnancies, decided that cooperation was worthwhile and over the next two years this cooperation became the catalyst for the current high involvement of healthcare professionals and patients in 4S. Figure 1 and 2 illustrates being monitored at the hospital and at home for a woman with a complicated pregnancy. Being monitored at the hospital typically means hospitalization for eight to ten weeks. This is one of the reasons why many prefer tele-monitoring.

\section{Developing the role of the board:}

\section{From project focus to national goals}

The board of 4S consisted of IT-managers from the three regions developing OpenTele, a representative from the organizations that developed the Net4Care infrastructure toolbox, a medical representative from the organizations that used OpenTele, and two representatives from the national level. Shortly after the formalization of $4 \mathrm{~S}$ an ITmanager from a large municipality joined the board. A PD researcher from the organizations that developed the infrastructure toolbox had the role of CEO on a part time basis.

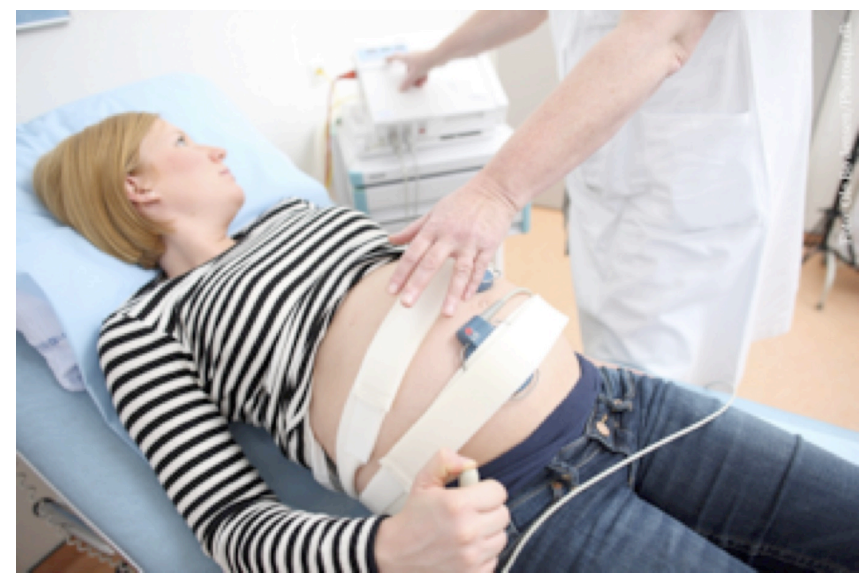

Figure 1. Monitoring at the hospital.

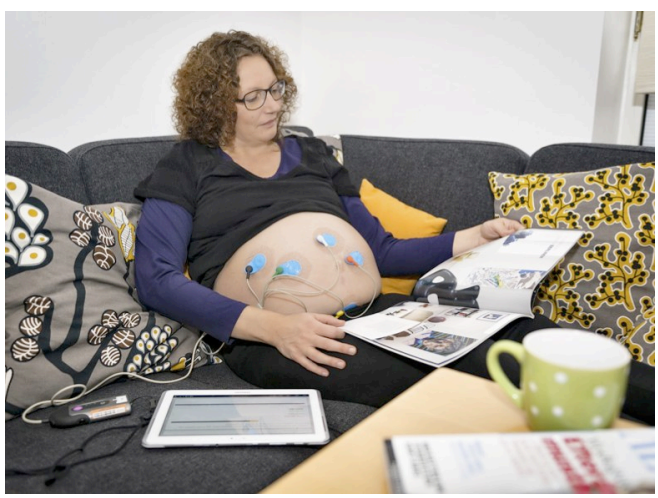

Figure 2. Monitoring at home.

A major task that the board wanted to work with was the creation of synergy in the continued development of OpenTele. This development was distributed across the two large projects and one of these projects consisted of five almost independent sub-projects. Thus on the one hand coordination and creating synergy might be difficult. On the other hand, the composition of the board made the members believe that they could orchestrate this. As it turned out, the "project logic" overruled most of the efforts aimed at creating synergy. This project logic emerged form time schedules so tight that coordination often was impossible and that analysis of alternatives never happened. On the positive side, the problems in creating synergy have increased the willingness on behalf of the regions to give more power to $4 \mathrm{~S}$ in the development of plans for the future of the OpenTele platform.

\section{Involvement of healthcare professionals and patients}

Democratic control by healthcare professionals and patients/citizens was not on the original agenda of $4 \mathrm{~S}$, but it was the intention to use $4 \mathrm{~S}$ to supplement the current influence by managers and IT developers with input from users. 4S chose to make this visible through the organizational structure, which consists of the abovementioned board, a software group and healthcare forums. Especially the forum on complicated pregnancies was an active participant in fieldwork-based evaluations and in organizing workshops with pregnant women and healthcare professionals to generate suggestions for improvements of OpenTele, cf. Figure 3 below.

This forum was also responsible for organizing the first national workshop for healthcare professionals on the use of telehealth for complicated pregnancies. 


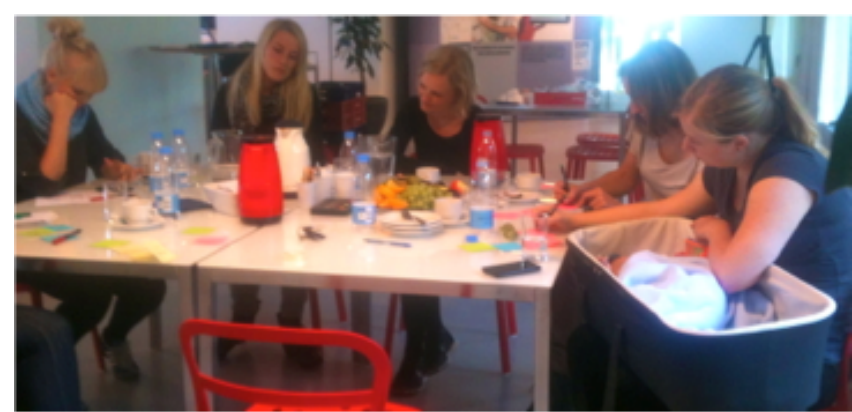

Figure 3. Workshop with pregnant women, and women who had recently given birth, to generate suggestions for improvements of OpenTele.

\section{Governance and handling of the open source software}

The last area that we worked with concerned all the traditional stuff related to governance of open source software, such as setting up a code repository and developing processes for quality control when modifying or adding software, including bug-tracking. It also included documentation, tutorials and discussion forums. In addition we wanted to develop standard contracts to be used by healthcare providers when contracting work based on the $4 \mathrm{~S}$ software.

When we look at the ability to realize these goals there is a marked difference between the infrastructure toolbox and the OpenTele platform. With respect to the toolbox all the relevant goals have been met. This is primarily due to the fact that the group behind the formation of $4 \mathrm{~S}$ also developed the toolbox and that this group actively promotes $4 \mathrm{~S}$ and involves others in the continued development of the toolbox. This includes involving both private companies and national organizations working with telehealth. In addition no tight timetables are currently involved.

When IT comes to OpenTele, the situation is - for several reasons - very different. First of all the OpenTele software uploaded to the $4 \mathrm{~S}$ code repository has so far been several steps behind the current versions used by the two telehealth projects.

The three regions paying for OpenTele want $4 \mathrm{~S}$ to have the most recent code. However, transfer of real governance - as opposed to formal governance, described in documents and transfer of code from the company originally developing OpenTele to $4 \mathrm{~S}$ was never part of the "project logic" mentioned above. Thus the regions have so far failed to allocated the necessary resources and "decision power" to speed up this transfer. And the private company responsible for the versions used by the telehealth projects has currently no real incentives to change this. The situation is, however, not satisfactory, and the $4 \mathrm{~S}$ board have recently decided to set up a timetable for finishing the transfer.

\section{Realizing the Democratic Potential}

It was the intension of all $4 \mathrm{~S}$ board members that a number of different companies should begin to develop new or revised modules for the OpenTele platform, e.g. a module supporting the use of smart watches or a better visualization of different health data. However, nothing happened, and in the spring of 2014 only the company that developed the original OpenTele solution was developing on OpenTele. Therefore $4 \mathrm{~S}$ decided that the research group behind the infrastructure toolbox should step in and develop a small number of new modules as well as some modifications to existing modules in close cooperation with healthcare professionals and patients, cf. Figure 4 below.

Through this we learned a lot about what was needed to facilitate a multi-vendor strategy and - even more important - we realized that $4 \mathrm{~S}$ had the potential to become an organizational frame for democratic influence in the area of telehealth through the control of the open source platform OpenTele and the possibilities for continued development of the platform based on Participatory Design (PD). Briefly stated we advocate $\mathrm{PD}$ as a way to develop great contributions with respect to both IT and organization. We advocate $4 \mathrm{~S}$ as a way of keeping control over the software and its development. And we advocate open source as a way of creating competition among different solutions and providers - ranging from research groups to private companies - in a way that will enhance quality and keep the costs down.

\section{Supporting a Societal Trend: The Next Tasks, Opportunities and Challenges}

In January 2015 the five Danish regions decided to implement infrastructure for telehealth within two years, and to do so based on the national reference architecture, thus increasing the importance of the $4 \mathrm{~S}$ infrastructure toolbox. Secondly, they decided that the main elements of the OpenTele platform should form the basis for telehealth solutions. These decisions open new possibilities of influence for $4 \mathrm{~S}$. At the same time the decisions imply that several different actors will want to exercise influence on $4 \mathrm{~S}$. Thus those interested in the democratic aspects of $4 \mathrm{~S}$ should step up their efforts in order not to be marginalized.

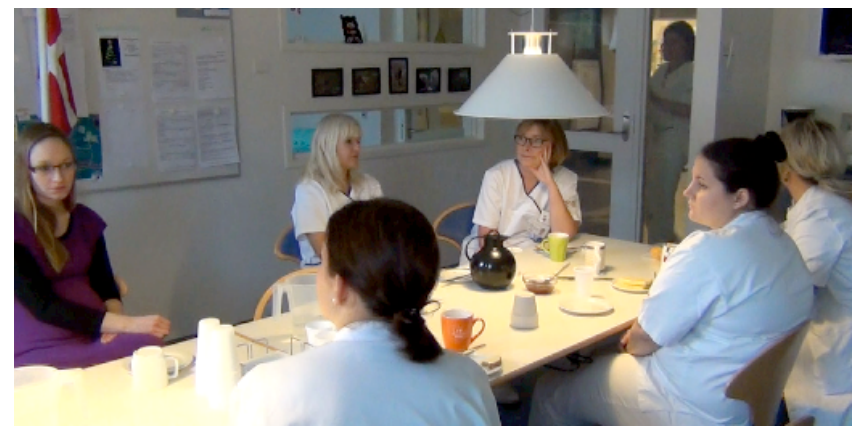

Figure 4. Workshop with health personnel and a pregnant women to generate suggestions for improvements in the use of OpenTele at the hospital and improvements to OpenTele itself. 
First of all, as part of this increased focus on promoting "democracy and PD", the key people behind the democratic aspects of 4S, i.e. PD researchers and healthcare professionals, realized that "creating great solutions via PD" and "keeping control over software via 4S" wasn't enough to create the interest and engagement that was needed. Based on our discussion with different healthcare professionals working at public hospitals that experienced continual budget cuts, we realized that many saw $4 \mathrm{~S}$ as a way of "fighting back". If not literally, then in terms of providing solutions and opportunities for development that wasn't depending on private companies and their profits. So this became the new story that made $4 \mathrm{~S}$ attractive to many healthcare workers. And - as discussed in the next section a story that was aligned with a growing societal trend of "fighting back" when tax cuts and public budget cuts were presented by governments as the only way forward.

As part of developing this aspect of $4 \mathrm{~S}$ we have begun to orchestrate critical debate, sharing of experiences and ideas among healthcare professionals, patients, citizens, public healthcare organizations and researchers. In addition $4 \mathrm{~S}$ facilitate cooperation among them - also when they do not agree. As it turned out, the decision by the five regions to implement infrastructure for telehealth caused major disputes to develop with the municipalities that are responsible for public home care. In this situation, $4 \mathrm{~S}$ succeeded in organizing a series of workshops and meetings to develop a compromise. However, looking at the current options for the above-mentioned groups, we find that especially patients and citizens as well as healthcare professionals need new venues and opportunities. $4 \mathrm{~S}$ has begun doing this through our health forums, cf. [1], and to our knowledge 4S is the only Danish organization facilitating this kind of activity. In addition to the activities organized by the health forums we have just begun the process of having a representative from a patient organization join the board.

Secondly, 4S is developing its role as an active partner in creation of PD projects within telehealth aimed at adding to and improving the $4 \mathrm{~S}$ software. However, the explicit focus on PD is new and we only have a few results so far.

Thirdly, 4S continues to improve its open source code repositories and processes for accessing and delivering code. These processes facilitate the transfer of results of successful, relevant PD projects to the open source software controlled by $4 \mathrm{~S}$. This includes documentation, quality control and CE Marking according to e.g. the Medical Device Directive of the European Union.

Finally, 4S continue to provide and improve resources that facilitate use of the $4 \mathrm{~S}$ software. The plan for the next 18 months includes texts on telehealth for patients and healthcare professionals, material on open source business models for customers and suppliers, as well as blue prints for contracts covering development, maintenance and operation.

\section{WHY 4S MIGHT SUCCEED}

In this section we first look at telehealth using different disciplinary perspectives that we find to be important in understanding the possibilities open to $4 \mathrm{~S}$. These perspectives include innovation, software ecosystems, open source, public finances, and Participatory Design.

Based on this understanding we then look at the different stakeholders in telehealth in Denmark and in $4 \mathrm{~S}$. We discuss their interests and how different aspect of $4 \mathrm{~S}$ may make them positive, neutral or negative.

\section{Innovation}

Telehealth, including telemedicine, has been around for many years. However, there are no widely used set-ups, no widely recognized good business cases and no big players with a strong, successful product, cf. e.g. [10-12]. Thus we may characterize telehealth as an emerging area in the sense that there are no so called dominant designs [13]. We may also say that telehealth is in the fluid stage. In this stage different actors experiment with new functionalities, user involvement is common and solutions are often flexible but ineffective [14]. To make an analogy from the area of products, we may look at the tablet computer. In 1989 GRiD Systems released the fist commercially available tablet-type portable computer [15]. But the fluid stage continued for more than two decades and only ended when Apple introduced the iPad, which quickly established itself as the leader among a few dominant designs. During the fluid stage the basic concepts or designs change quite often, new players have a reasonable chance of success and cooperation with users increases the chance of success [13]. Drawing on C. Christens notion of disruptive technology [16] we also observe that new players have especially good chances of success in the cases where they develop new types of solutions to a new market and these solutions only later become interesting in one or more big, established markets. Thus in the area of telehealth, a small new organization like $4 \mathrm{~S}$ may have a much better chance than a similar effort directed towards say Electronic Patient Records, an established area dominated by multi billion dollar companies like Epic Systems Corporation [17]. And if solutions in the telehealth area develop in ways that over time make them attractive also in relation to other kinds of hospital-based healthcare services, then theories like those of C. Christensen tell us that small players like 4S have a reasonable chance of entering the bigger market of say hospital IT systems.

\section{Software ecosystems}

Our first ideas on creating $4 \mathrm{~S}$ to promote and further develop an open source IT-infrastructure toolbox was subsequently rephrased, analyzed, and further developed using concepts from the area of software ecosystems. The research field of software ecosystems has emerged as the study of complex interactions between software frameworks and software architectures on one hand, and 
organizations, users, customers, developers, and businesses on the other. Based on a recent literature review [18] we define a 'software ecosystem' as: 'the interaction of a set of actors on top of a common technological platform that results in a number of software solutions or services". Further, "Each actor is motivated by a set of interests or business models and connected to the rest of the actors and the ecosystem as a whole with symbiotic relationships, while, the technological platform is structured in a way that allows the involvement and contribution of the different actors." Well-known examples of software ecosystems are the Apple iOS and Google Android ecosystems respectively. The telehealth ecosystem in Denmark is a very different story, but all the same we were able to use the software ecosystem concepts to analyze the status quo, identify the lack of connectivity as a key issue, and to argue for the possibility to improve the ecosystem through the creation of $4 \mathrm{~S}$ and an active guardianship of the Net4Care infrastructure toolbox. We also learned that $4 \mathrm{~S}$ should pay specific attention to the "interests or business models" of all major actors. Regarding the infrastructure toolbox itself, this worked quite well. The toolbox was seen as a useful, and it did not compete with any existing products. However, our inclusion of the telehealth platform OpenTele, challenged our relationship with many private vendors, which viewed OpenTele as a direct competitor to their closed source solutions. Subsequently we have worked directly on developing business models that illustrate how different kinds of vendors may benefit from both the infrastructure toolbox and the telehealth platform. As of mid 2015 several of the main, private actors of different kinds are positive or neutral towards $4 \mathrm{~S}$ including the OpenTele platform as illustrated by a recent press release from the Danish Regions co-signed by the Confederation of Danish Industry [19]. For more on $4 \mathrm{~S}$ in a software ecosystem perspective se [6].

\section{Open Source}

Open source was chosen for both the infrastructure toolbox and the OpenTele platform early on, i.e. prior to the formation of $4 \mathrm{~S}$. With respect to the toolbox is was a natural choice for modules that we intended to be used in as many telehealth - and other health-IT - systems as possible. It was also an approach we had used earlier in EU research projects developing infrastructure tools cf. [7]. Concerning the OpenTele platform, the decision to use open source was made by the three regions financing the development. One reason for this decision was their experiences with licensebased payment models for some commercial telemedicine systems. While these models were acceptable in small to medium sized pilots, they presented - in the view of the regions - an unacceptable price tag when scaling up. Open source was seen as a way of getting rid of the license fees. In addition, open source was seen as a way to realize a multi vendor strategy that would support both better quality and competitive prices. For the company developing the first versions of OpenTele, open source was probably important because this made it possible for the company to develop new versions for new markets without having to negotiate with any owners of the software. Looking back, the decision to use open source has proven to be very important in the development of support for the $4 \mathrm{~S}$ vision of democratic control and PD. This is discussed below.

\section{Public finances and tax evasion}

The healthcare systems around the world are under increased pressure: populations are growing, the percentage of elderly and old people is increasing, and the number of possible treatments is growing, as are the costs of medicine. In addition the expected level of public service is growing in countries like Denmark. As a result current models for financing public health are in general considered not to be sustainable, see e.g. [20]. In this situation many governments look to telehealth as a way to keep expenditure under control. However, so far such expectations have not been validated, se e.g. [10, 11].

The most common conclusion seems to be that telehealth is not one specific thing, and that the way different elements are put together and integrated in context is what results in bad, neutral or god outcomes for the different stakeholders [21]. Following this line of thought we find that $4 \mathrm{~S}$ offers two important possibilities: First of all the infrastructure toolbox and the OpenTele platform make it possible to tailor many different kinds of telehealth solutions, and to integrate these with other types of health IT systems in many different ways. Secondly, since both the toolbox and OpenTele are open source, it is possible to use and modify them in experiments, and then - based on the $4 \mathrm{~S}$ processes for quality control - transfer results into the $4 \mathrm{~S}$ code base and use them in large-scale operation.

In addition, the debate on financing the modern well-fare state has changed in recent years. For many people it is no longer only a question of how to control public spending, but also a question of how to counteract unfair rules and regulations as well as systematic tax evasion by big international corporations - tax evasion on a scale that threatens national coherence through extreme inequality, cf. [22] and, for a discussion of these issues related to innovation, [23]. As it turned out, this changed public climate makes it possible to tell the story about $4 \mathrm{~S}$ as a way of providing a democratic alternative to big corporations with flawed tax morale. In many cases, where we have discussed the possibility to use OpenTele with hospital personnel, this aspect of $4 \mathrm{~S}$ has played an important role. Especially in situations where hospital budgets are being reduced, the idea of having a non-profit, public organization like $4 \mathrm{~S}$ governing open source software is very attractive to many hospital employees.

\section{Participatory Design}

Participatory Design has, since is emergence in the early 1970 s, been seen as a vehicle for democratization of tech- 
nology, although views has varied quite a bit on how successful PD has been and are in this respect, see. e.g. [24-26]

In relation to our discussion of $4 \mathrm{~S}$ and why it might succeed we'll first look at the issue of visions and then consider partners and results.

\section{Visions}

Participatory Design, especially in the Scandinavian varieties, had from its formation in the early 1970s and the following two decades a strong and appealing vision based on work place democracy and more broadly democratization of technology. If we look at the activities and publications from this period it is obvious that this vision played a very important role when people chose to work with PD, see e.g. the volumes of the Scandinavian Journal of Information Systems cited above [24-26].

From the 1990s and on "work place democracy" faded and only the more abstract "democratizat $\neg$ ion of technology" remained. This change in vision meant that PD changed from being part of something that was important for trade unions and their members to something important for those who were involved in a PD project, and to PD researchers. One might characterize this as a change from political to academic. This development is also reflected in [27], where Shapiro argues that PD theoretically has the potential to produce better systems. This is a very important point for PD researches, but we have found it difficult to use this kind of argument to create engagement among patients and healthcare personnel. For example we found it difficult to convince users that PD is much better than agile development methods like say SCRUM [28].

The vision of 4S - democratic control, structures for sustaining such control, and continued development through Participatory Design projects - has created strong engagement from healthcare professionals and patients, much stronger than the abstract "democratization of technology."

\section{Partners and results}

In Scandinavia the first generation of projects (e.g. The Norwegian Iron and Metal workers project [29] focused on how local trade unions might influence managementcontrolled development and deployment of IT systems at the individual workplace in order to promote worker interests $[2,4]$. An important part of this work consisted of developing courses for local union people, including the teaching material used. Another element was national dataagreements that regulated the way management introduced ICT systems [3, 4].

In the second generation of projects (e.g. The UTOPIA project [30]) focus was on worker-controlled design of IT systems from a trade union perspective, both to generate demands when negotiating with management and to form the basis for development of specific systems by commercial companies. And once more, developing teaching material for the unions was an important element. In addition it turned out that existing system development methods were inadequate for this endeavor, and thus - by necessity - the researchers in the Utopia project began to develop tools and techniques for PD [31].

Looking at this list of results, it is not surprising that the trade unions was a very strong partner in the first two generations of project. They co-created the venues for debate and dissemination, and they were partners in a comprehensive educational effort based on the trade union educational programs for shop stewards. An example on this is the final report from the Utopia projects. It was written for graphical workers, printed in 70.000 copies and distributed by the Nordic unions to all their members.

Since the late 1990s focus in many, probably in most, PD projects has been on how best to involve people (users/potential users) in the development of ICT in ways that allow them to promote their own interests in relation to the ICT being developed. Focus is often on the project level, on PD tools and processes, and it seems that focus on structures outside the individual projects has decreased, see e.g. $[5,24-26,32]$.

At least two kinds of arguments have been used as explanations: the changing role of trade unions and "normalization" of use of technology [4]. The first argument assumes that the weakening role of trade unions over the last decades makes it difficult for PD researchers and/or trade unions to continue the kind of cooperation that the first and second generation of projects represented. In our view this is not substantiated: trade unions still have comprehensive course programs, they engage in struggles for organizing labor of different nationalities, including tracing opaque ownership relations, debates on the impact of globalization etc. We find it more likely that "normalization" plays an important role. Normalization refers to the changes in the use of technology at the workplace that have occurred since the early 1970s. Back then IT was new to the shop floor and the first generation of projects played an important role in helping the unions to understand potential implications of IT and how to deal with them.

When we consider the Utopia project, it took place at a time when information technology was about to dramatically change the newspaper industry - and once more this was a project that played an important role in helping the trade unions understand the potential implications and to develop a design of a system that represented an alternative to the major commercial products being developed.

During the 1990s and in the following decade the use of IT has become business as usual in many industries, and in our 
view, this is a primary reason why the projects of the first generations are difficult to "re-invent".

When we look at $4 \mathrm{~S}$ in this light we see that a strong partner like the unions is missing. However, $4 \mathrm{~S}$ is addressing an area where the use of technology is emerging and about to dramatically change treatment, rehabilitation and prevention. Thus $4 \mathrm{~S}$ is producing a number of results, which makes $4 \mathrm{~S}$ very relevant to large numbers of healthcare professionals, citizens and citizen organizations as well as to patients and patient organizations. Thus we find that $4 \mathrm{~S}$ has the potential to expand its role as a part of the discourse on telehealth among these groups and to facilitate development of e.g. courses on telehealth for home care nurses and different patient groups. In addition $4 \mathrm{~S}$ is currently facilitating a small, but growing number of PD projects aimed at improving telehealth, for patients/citizens and healthcare professionals, as well as for the public healthcare providers. The results of these projects are sustained by transferring the software to the $4 \mathrm{~S}$ OpenTele code base and by making the relevant documentation, organizational models, course material etc. available through $4 \mathrm{~S}$.

\section{The Stakeholders in Telemedicine}

As the next part of analyzing why $4 \mathrm{~S}$ might be a success we consider the different stakeholders and their interests in $4 \mathrm{~S}$. In doing so we also summarize the interests of each group across the disciplinary discussion in the previous subsections. However, to set the scene we first look at some of the key ideas and assumptions from the first generations of Scandinavian PD projects.

First of all we note that the first Scandinavian PD projects, like the Iron and Metal Workers project [29] and the Utopia project [30] aimed at improving work by changing the way computers were used at the workplace. To do so they focused on cooperation between researchers and trade unions. However, to achieve the improvements aimed at, the idea was that the trade unions would subsequently use the knowledge and other results from the projects to negotiate such improvements with management and owners, both locally and centrally. In [5], Kyng labels this

\footnotetext{
${ }^{2}$ Early examples on suggestions for where to look for new possibilities for PD include working in developing countries and with non-profit organizations. Both these lines of work have resulted in new projects, but not on a scale like the first generations of Scandinavian projects. Recently several new forms of extremely individualized labor are emerging in e.g. programming, translation and transportation. It has, in discussions among PD researchers, been suggested that PD researchers should look into making a new kind of PD-project to help understand what is going on and how to counteract negative consequences. To our knowledge such a project hasn't been initiated yet.
}

line of reasoning Concrete Consensus, and describe it in the following way:

- The system and organization of work/activities will have positive effects for both users/employees and for buyers/employers (representing the owners of the organization using the system).

- It is possible to find or establish one or more companies that will implement and market the system.

- A market exists for the system, i.e. there are companies/individuals who will buy it.

The Utopia project designed a system that probably fulfilled the first bullet, failed with the second, and thus did not provide real information on the third [30].

In our analysis of the possibilities of $4 \mathrm{~S}$ to succeed in providing substantial improvements for patients/citizens and healthcare personnel, we use the above notion of concrete consensus as a way of understanding how the interests of patients/citizens and healthcare personnel may co-exist with the interests of other stakeholders.

\section{The users}

The primary users are patients/citizens and healthcare personnel. Both these groups are experiencing major changes affecting their daily life or work when telehealth is introduced. However, the consequences vary depending on the solution in question. Currently no obviously good solutions covering both IT and organization exist, but both groups, and especially the patients, give the current OpenTele solutions high rankings. The groups may influence the development of OpenTele through $4 \mathrm{~S}$, both via the board and via PD projects. Concerning the $4 \mathrm{~S} P D$ projects we see the same possibilities and pitfalls as in other PD projects in the healthcare area. These include asymmetric power relations and often the lack of a strong network and other resources on the patient side, se e.g. [3336]. When it comes to the board we expect patient/citizen organizations to play a major role, since the individual patient or citizen do not have the resources, and since these organizations already are actively involved in promoting patient/citizen interests in relation to health and welfare technology, including telehealth. Thus it will be the responsibility of these organizations to safeguard against patients/citizens becoming hostages for other interests. With respect to healthcare personnel we are not sure how they will utilize the board. Currently the healthcare personnel participate based on their involvement in telehealth projects and as telehealth experts recognized by their peers. At the moment the professional organizations, e.g. the Danish Medical Association, are not actively involved in the area of telehealth. Thus the healthcare personnel currently involved in $4 \mathrm{~S}$ also see $4 \mathrm{~S}$ as a way of developing policies on behalf of their respective professional organizations. 
The providers of health services

The hospitals and other providers of health services in Denmark are expected to introduce telehealth in the next few years and to reduce costs and increase quality by doing so. However, as previously mentioned, there are no hard data supporting that they can achieve this. Thus many of the providers of health services see a need for building more knowledge and developing and modifying telehealth solutions based on experiences. And for these reasons they engage in $4 \mathrm{~S}$. At the same time they acknowledge that the users of telehealth should play a key role in this, and therefore welcome the emphasis that $4 \mathrm{~S}$ place on the influence of there groups.

In the future we will see differences between the different user groups and between these groups and the managers representing the providers of health services when it comes to specific solutions. So far we believe that the possibilities offered to the users by $4 \mathrm{~S}$, will make it easier for them to promote their own interests - also, and maybe especially, in the face of disagreements with management.

\section{The public authorities financing health services}

In Denmark, the Ministry of Health and the municipalities finance health services. As mentioned they expect telehealth to deliver substantial savings, but they too know that there are no hard data supporting this. At the same time, they consider the economic models for the primary, commercial telehealth solutions to be too expensive when scaling up to the national level. Thus, for the same reasons as the providers of health services, they are positive towards $4 \mathrm{~S}$. They also see $4 \mathrm{~S}$ as way to develop business models and cost structures that are beneficial for the different public stakeholders. At the same time they expect the $4 \mathrm{~S}$ infrastructure toolbox to speed up data sharing and the integration of telehealth solutions with other types of health IT and thus pave the way for better economy in telehealth.

\section{Suppliers of health IT}

The last group of stakeholders we consider are companies providing health IT. Several of these companies have made substantial investments in the area of telehealth and many of them find that the public customers should just buy their solutions and get on with the job of providing telehealth services $^{3}$. However, this is not really happening. The markets for telehealth are small and fragmented, and most of the customers postpone purchases. In this situation the $4 \mathrm{~S}$ infrastructure toolbox is seen as a way to integrate proprietary solutions from different vendors and thus support growing market integration. In addition the contributions from $4 \mathrm{~S}$ to building knowledge among public customers is also seen as a way to speed up their decisions on buying telehealth solutions. When it comes to the

\footnotetext{
${ }^{3}$ Personal communication with managers from several big, international IT companies from 2008 to the present.
}

OpenTele platform, this is being accepted as a fact of life, i.e. as a decision made by the regions, not by $4 \mathrm{~S}$. In this situation many private companies see $4 \mathrm{~S}$ as making positive contributions, e.g. in terms of suggesting business models for different types of companies and developing processes for accessing and delivering code that make use of the OpenTele platform attractive for a number of different types of companies.

In summary, $4 \mathrm{~S}$ promotes OpenTele solutions, but aim for co-existence with other solutions, not for confrontation. Actually $4 \mathrm{~S}$ actively facilitate co-existence based on datasharing and integration through the infrastructure toolbox. And in doing so it seems that $4 \mathrm{~S}$ is creating support from most of the stakeholders and that only a rather small minority is now negative towards $4 \mathrm{~S}$.

This being said, quite a few people, both in the public and the private sector, are skeptical towards open source, and we expect this skepticism to continue to influence also how they view $4 \mathrm{~S}$.

Finally, it should be noted that the vision of $4 \mathrm{~S}$ means different things to different people. To many, and probably to the most enthusiastic supporters, it is important that $4 \mathrm{~S}$ provides a democratic alternative to big corporations with flawed morale concerning tax. To others, $4 \mathrm{~S}$ is important as a way of sustaining results of PD projects. And to managers at hospitals and regional IT departments, $4 \mathrm{~S}$ is a way of combining development of cost-effective solutions with user involvement and acceptance.

\section{DISCUSSION}

$4 \mathrm{~S}$ today is emerging as an organization that sustains democratic control by healthcare professionals and patients/citizens. However, that $4 \mathrm{~S}$ ended up in this way is at least as surprising to the researchers who took the initiative to create $4 \mathrm{~S}$ as it was to the researchers creating the Utopia project, that the main heritage of that project probably is contributions to PD tools and techniques. In the following we discuss these two issues: Fist we look at sustaining democratic control and related work in PD. Then we briefly discuss the issue of surprise, and we do so under the heading "Why this took a long time".

\section{On Participatory Design and sustaining democracy}

Following the first generations of Scandinavian PD projects, PD research has focused primarily on PD tools and techniques, see e.g. [3, 5, 32]. The PDC 2012 proceedings, [32] does contain a session on values and politics, ibid pp. 29-40. However, of the three papers in the session two are about methods and techniques and the third is about how children with profound disabilities can participate in formative design processes. All three papers represent interesting and valid contributions, but they are not related to politics in the sense of the first Scandinavian PD projects. From time to time this development results in discussions of how to reinforce or even reinstate ideals on 
democracy and political action. This was discussed e.g. by Kyng in [4], where he pointed to "normalization" of the use of IT at workplaces as one of the reasons of declining cooperation with Trade Unions in PD. In [3] Bødker et al list a number of changes in technology, management, unions and research which they all see as contributing to the shift from political to pragmatic. They also explain the huge success of PD as largely depending on participation being a basic epistemological (knowledge theoretical) principle. At the same time, they are not willing to let go of the political aspects of the past. They discuss the "consumer movement" as one promising possibility, and mention the computer equipment certification by TCO, the Swedish Confederation of professional employees, see also [37]. The most vivid debate of the development of PD research is probably the 2002 and 2003 issues of the Scandinavian Journal of Information Systems, where the titles of the papers include "P for Political", "D for Democracy", and "A for Alternatives". In "P for Political" [38], it is argued that "PD must encompass work motivated in political conscience, ...not only participatory design." An almost alternative view is presented by Kyng in [5], who argues that the politics in PD relies on external factors, e.g. Trade Unions. When we then look at where $4 \mathrm{~S}$ may be positioned is this debate, we find that the $4 \mathrm{~S}$ initiative has developed into being political, in the sense that it facilitates democratic control over IT solutions by users and their organizations. However, the mechanism for this control, the 4S organization, is not PD or a result of PD, but an "external factor" that uses PD to develop solutions in the interests of users. And $4 \mathrm{~S}$ in turn, is itself dependent on the growing societal trend of "fighting back" when tax cuts and public budget cuts are presented by governments as the only way forward.

\section{What about sustaining results?}

A different line of reflection in PD is represented by the investigations into sustaining results of PD projects.

The paper by Iversen and Dindler [39] reviews a number of papers on sustaining PD initiatives and identifies four different forms of sustaining: maintaining, scaling, replicating, and evolving. They go on to discuss how to increase sustainability based on the more nuanced understanding that the different forms represent. The paper concludes, "in general, the sustainability perspective does not fundamentally change the PD toolbox, but may influence the choice of method, how they are modified and when they are used." p. 166. We agree with the main points presented in the paper. However, we note that the paper is about sustaining of the results of PD projects. And we find that the options discussed for improving sustainability of results are framed by the notion of a project. In contrast to this approach, the $4 \mathrm{~S}$ initiative sets up a new, potentially permanent, organization to sustain results - and to frame PD projects. The $4 \mathrm{~S}$ approach also solves another issue related to sustaining results: that of keeping control of results over time. The issue is illustrated by a PD project that developed a system for hospital operation room logistics. The system received very positive evaluations by health care personnel [40]. Among other things they pointed to improved work environment. Later a privately owned company was formed to turn the system into a product, and that company was recently sold for almost 20 million dollars. The current web-site for the company emphasizes improved productivity, and do not mention work environment [41].

\section{Why this took a long time}

Looking back at the history of $4 \mathrm{~S}$, we note that it took us a long time to move from the initial ideas on $4 \mathrm{~S}$ to the current vision and organization. And when we began to think about this, we found it especially surprising that it took us so long to make the connection between $4 \mathrm{~S}$ and PD. However, today we believe that this delay is understandable.

First of all we note that it is common knowledge that people tend to stick proven ways of doing things for (too) long, se also [13]. One might say that the success and tradition of PD research made us blind to other ways of doing than continuing current PD research with its focus on PD methods, techniques and tools - and on the concept of a project as the frame for doing things.

Secondly, we note that we were equally slow in understanding and developing the democratic potential of $4 \mathrm{~S}$. In retrospect one might say that we were not looking for democracy, and thus we did not see it for a very long time. In addition, the researchers involved in the creation of $4 \mathrm{~S}$, adhere to the notion that politics in PD relies mainly on external factors. Thus we did not want to push for the "fighting back" part of the $4 \mathrm{~S}$ vision, but to develop it together with key players among the users.

If this understanding will help others to move faster and more effectively when creating alternatives and mechanisms to sustain them we are not quite sure. However, a simple lesson for PD researchers could be that there is more to democracy and politics than PD and projects, a subject that we expand a bit upon in the section below.

\section{CONCLUSIONS}

The story of $4 \mathrm{~S}$ is quite specific: IT is about telehealth in Denmark and how an organization set up to govern open source software developed into a frame for sustaining democratic control and PD projects. On the other hand we find that the story illustrates some key points in the discussions on PD and democracy.

First of all 4S illustrates how PD may become part of a societal trend, and that the specific aspects of that trend are important for the outcome. In our case fighting back when tax cuts and public budget cuts are presented by governments as the only way forward. 
Secondly, 4S illustrates how proper support structures for the participants/users and their "group interests" are important and at the same time that developing these structures are not, or at least need not be, part of the results of PD, at lest not explicit, consciously executed PD.

Thirdly, we find that 4S illustrates that "Democracy" or "Democratic control" often are too general categories to create enthusiasm and engagement, there has to be a manifestation of a more concrete vision, 'problem' and 'solution'.

When we turn to the possibilities for doing something analogue in other countries we are mildly positive: in countries with sufficiently similar political systems and health systems, it seems worthwhile to investigate if and how cooperation between $4 \mathrm{~S}$ and matching organizations might be feasible. On a very practical level, we are talking with the Greek organization "SciFY - Open Source software/hardware for social benefit" and the Faculty of medicine, University of Thessaly, about using OpenTele to deliver telemedicine in small villages in rural areas where access to medical assistance is difficult.

When it comes to possibilities for doing something analogue in another specific area, a first step could be to carry out an analysis of that area, similar to the one presented in the section Why $4 \mathrm{~S}$ might succeed. And then, based on this initial understanding, develop a more targeted analysis, tailored to the specifics of the area in question.

\section{FUTURE WORK IN THE PD RESEARCH ARENA}

Up until now the $4 \mathrm{~S}$ initiative have been about creating and developing the 4S organization and using "state-of-the art" PD within this framework. However, we expect that the future activities of $4 \mathrm{~S}$ will provide numerous opportunities for PD research. Issues we would like to address include PD processes for going from successful research prototype via clinical trials to tested and certified software. And from small-scale pilot to large-scale daily operation. Furthermore we see a strong need for PD to cooperate with other disciplines to encompass work on business models, e.g. for starts-ups working with the $4 \mathrm{~S}$ software, and on the socalled business cases used by e.g. public providers of health services to evaluate new service proposals. Up until now these business cases have mainly been using quite standard economic concepts and models. Hopefully PD can contribute to the development of supplementary concepts and models.

\section{ACKNOWLEDGMENTS}

We thank all the people involved in the $4 \mathrm{~S}$ initiative, and especially the healthcare personnel and the pregnant women in the sub-project on complicated pregnancies at Aarhus University Hospital. In addition we thank the reviewers for their comments.

\section{REFERENCES}

1. 4S webpage. Available from: http://4S-online.dk.

2. Ehn, P. and M. Kyng, The Collective Resource Approach to Systems Design, in Computers and Democracy. 1987, Avebury: Aldershot, UK. p. 17-57.

3. Bødker, S., et al., Co-operative Design-perspectives on 20 years with 'the Scandinavian IT Design Model', in Proceedings of NordiCHI 2000. 2000: Stockholm, Sweden. p. 22-24.

4. Kyng, M., Users and computers: A contextual approach to design of computer artifacts.

Scandinavian Journal of Information Systems, 1998. 10(1\&2): p. 7-44.

5. Kyng, M., Bridging the Gap Between Politics and Techniques: On the next practices of participatory design. Scandinavian Journal of Information Systems, 2010. 22(1): p. 49-68.

6. Christensen, H.B., et al., Analysis and design of software ecosystem architectures - Towards the $4 S$ telemedicine ecosystem. Special issue on Software Ecosystems, 2014. 56(11): p. 1476-1492.

7. PalCom project webpage. Available from: http://www.ist-palcom.org/.

8. Statens Serum, I. and I.T. National Sundheds, Referencearkitektur for opsamling af helbredsdata hos borgeren. 2013, National Sundheds-IT: København.

9. The UNIK partnership conference. 2013; Available from: http://www.partnerskabetunik.dk/media/38318/opdate ret invitation.pdf.

10. Steventon, A., et al., Effect of telehealth on use of secondary care and mortality: findings from the Whole System Demonstrator cluster randomised trial. BMJ (Clinical research ed.), 2012. 344: p. e3874.

11. EU project Renewing Health. Available from: http://www.renewinghealth.eu/en/.

12. the Telecare Nord project on COPD. Available from: http://www.rn.dk/Sundhed/Til-sundhedsfaglige-ogsamarbejdspartnere/TeleCare-Nord.

13. Tidd, J. and J. Bessant, Managing innovation : integrating technological, market and organizational change. Vol. 4th. 2009, New York: Wiley. 638.

14. Abernathy, W. and J. Utterback, Patterns of industrial innovation. MIT Technology Review, 1978(6): p. 4047.

15. The BYTE awards : GRID System's GRiDPad. BYTE Magazine, 1990. 15(1): p. 285-286.

16. Christensen, C.M., The Innovator's Dilemma : When New Technologies Cause Great Firms to Fail. 1997, Harward: Harvars Business Press. 225.

17. Epic Systems Corporation. Available from: http://en.wikipedia.org/wiki/Epic Systems

18. Manikas, K. and K.M. Hansen, Software ecosystems A systematic literature review. Journal of Systems and Software, 2013. 86(5): p. 1294-1306.

19. Falles vej frem for telemedicin til glade for både patienter og erhvervsliv. 02.02.2015; Available from: 
http://www.regioner.dk/aktuelt/nyheder/2015/februar/f $\% \mathrm{C} 3 \%$ A6lles + vej+frem+for+telemedicin + til $+\mathrm{gl} \% \mathrm{C} 3$ $\% \mathrm{~A} 6 \mathrm{de}+$ for $+\mathrm{b} \% \mathrm{C} 3 \% \mathrm{~A} 5 \mathrm{de}+$ patienter + og + erhvervsliv.

20. Porter, M. June 6, 2006, Mandag Morgen: Copenhagen, Denmark.

21. Goodwin, N., Jumping the gun in the telehealth steeplechase. 2012.

22. Piketty, T., Capital in the Twenty-First Century. 2014: Harvard University Press.

23. Mazzucato, M., The entrepreneurial state : debunking public vs. private sector myths. Anthem frontiers of global political economy. 2013, London: Anthem Press. 237.

24. Scandinavian J of Information Systems, 1998. 10.

25. Scandinavian J of Information Systems, 2003. 15.

26. Scandinavian J of Information Systems, 2010. 22.

27. Shapiro, D., Participatory design: the will to succeed, in Proceedings of the 4th decennial conference on Critical computing: between sense and sensibility. 2005, ACM: Aarhus, Denmark. p. 29-38.

28. Schwaber, K. Controlled Chaos : Living on the Edge 1996.

29. Nygaard, K., The 'Iron and metal project': trade union participation, in Computers Dividing Man and Work-Recent Scandinavian Research on Planning and Computers from a Trade Union Perspective., Å. Sandberg, Editor. 1979, Swedish Center for Working Life, Demos Project report no. 13, Utbildningsproduktion: Malmö, Sweden. p. 94-107.

30. Bødker, S., et al., A Utopian Experience. Proceedings of the 1986 Conference on Computers and Democracy, 1987: p. 251-278.

31. Ehn, P. and M. Kyng, Cardboard Computers: Mocking-it-up or Hands-on the Future, in Design at work: Cooperative design of computer systems, J. Greenbaum and M. Kyng, Editors. 1991, Lawrence Erlbaum Associates, Inc.: Hillsdale, New Jersey, USA. p. 169-195.
32. Proceedings of PDC 2012, The Participatory Design Conference. 2012: Roskilde, Denmark.

33. Grönvall, E. and M. Kyng, Beyond Utopia: reflections on participatory design in home-based healthcare with weak users, in Proceedings of the 29th Annual European Conference on Cognitive Ergonomics. 2011, ACM: Rostock, Germany. p. 189-196.

34. Christensen, L.R. and E. Grönvall, Challenges and Opportunities for Collaborative Technologies for Home Care Work, in ECSCW 2011: Proceedings of the 12th European Conference on Computer Supported Cooperative Work, 24-28 September 2011, Aarhus Denmark, S. Bødker, et al., Editors. 2011, Springer London. p. 61-80.

35. Fitzpatrick, G. and G. Ellingsen, A Review of 25 Years of CSCW Research in Healthcare: Contributions, Challenges and Future Agendas. Computer Supported Cooperative Work (CSCW), 2012: p. 1-57.

36. Bertelsen, W.O., et al., Therapeutic Strategies - a Challenge for User Involvement in Design, in Workshop at NordiChi 2010, The 6th Nordic Conference on Human-Computer Interaction. 2010: Reykjavik, Iceland.

37. Gulliksen, J., et al., Key principles for user-centred systems design. Behaviour \& Information Technology, 2003. 22(6): p. 397-409.

38. Beck, E.E., P for Political: Participation is Not Enough. Scandinavian Journal of Information Systems, 2002. 14(1): p. 77-92.

39. Iversen, O.S. and C. Dindler, Sustaining participatory design initiatives. CoDesign: International Journal of CoCreation in Design and the Arts, 2014. 10(3-4): p. 153-170.

40. iHospital. Det Interaktive Hospital. 2005; Available from: http://www.ihospital.dk/.

41. Cetrea. Clinical Logostics. 2015; Available from: http://www.cetrea.com/index.php/en/. 